\title{
UMA HIPÓTESE CURRICULAR PARA A FORMAÇÃO CONTINUADA DE PROFESSORES DE CIÊNCIAS E DE MATEMÁTICA
}

\section{Science and Mathematics teachers' continuing education: a curricular hypothesis}

\author{
Carla Gonçalves Rodrigues ${ }^{1}$ \\ Verno Krüger ${ }^{2}$ \\ Alessandro Cury Soares ${ }^{3}$
}

Resumo: Este artigo relata o desenvolvimento e a análise de uma proposta curricular para a evolução das concepções didático-metodológicas de professores de Ciências e de Matemática do Ensino Básico. Essa proposta desenvolveu-se no contexto do Programa de Pós-Graduação em Educação da Faculdade de Educação da Universidade Federal de Pelotas. Os objetivos, a estrutura curricular e as metodologias de ensino utilizadas foram referenciados pela proposta de formação continuada de professores do Grupo DIE-IRES, da Universidade de Sevilla, Espanha, que tem como meta desejável, a formação de um professor autônomo e investigador de sua ação docente, em um processo no qual os saberes didático-metodológicos e disciplinares são conteúdos relevantes para a complexificação de seu conhecimento profissional e de sua prática pedagógica.

Palavras-chave: Ensino de Ciências e Matemática. Formação continuada de professores. Currículo.

\begin{abstract}
This paper describes the development and the analysis of a curricular proposal for basic educational level Science and Mathematics teachers' didactic-methodological conceptions evolution. This curricular proposal was carried out in the context of Pelotas Federal University' School of Education. Objectives, curricular structure, and teaching methodologies were guided by the DIEIRES Group from the University of Sevilla, Spain, on-going teacher formation proposal, which has, as a desirable goal, the formation of an autonomous and investigative teacher in a process in which his/ her didactic, methodological and disciplinary knowledge are considered essential for the complexification of his/her professional knowledge and his/her pedagogical practice.
\end{abstract}

Keywords: Teaching of Science and Mathematics. Teachers' continuing education. Curriculum.

\footnotetext{
${ }^{1}$ Licenciada em Matemática, doutora em Educação. Docente, Departamento de Ensino, Universidade Federal de Pelotas (UFPel). Pelotas, RS, Brasil.<cgrm@ufpel.tche.br>

${ }^{2}$ Licenciado em Química, doutor em Educação. Docente, Departamento de Ensino, UFPel. Pelotas, RS, Brasil. <kruger.verno@gmail.com>

${ }^{3}$ Licenciado em Química, mestrando em Educação em Ciências. Professor substituto, Departamento de Ensino, UFPel. Pelotas, RS, Brasil. <alessandrors80@hotmail.com>
}

${ }^{1}$ Av. Dom Joaquim, 529, apto. 301

Pelotas, RS

$96.020-260$ 


\section{Introdução}

Os contatos com professores dos nossos sistemas de ensino têm sido oportunidades para se identificar a existência de insatisfações tanto profissionais como em suas práticas docentes. Estas estão relacionadas com diversos fatores, tais como: questões salariais, a organização do sistema educacional, a ação docente e a aprendizagem dos alunos.

Com o objetivo de diminuir suas insatisfações, uma parte desses professores busca, num primeiro momento, as universidades, que são as tradicionais supridoras de referenciais e de modelos sobre a prática de ensino. Nestas, normalmente, são oferecidos, aos professores das escolas, "cursos de atualização", "treinamentos em habilidades específicas" ou cursos de especialização em conteúdos disciplinares, e que são, geralmente, estruturados de acordo com pressupostos formativos que privilegiam, fundamentalmente, um saber acadêmico entendido como acabado, verdadeiro, cumulativo e descontextualizado (PORLÁN e RIVERO, 1998).

Como na organização dessas propostas de formação continuada pouco se consideram os problemas concretos do cotidiano dos professores e o seu conhecimento profissional, o desenvolvimento desses cursos aumenta neles a sensação de impotência para resolver os problemas profissionais com os quais se defrontam na sua prática pedagógica. Observamos que uma das consequências desse modo operacional é o reforço de vínculos de dependência dos professores do Ensino Básico com as universidades, consideradas, no contexto da racionalidade técnica vigente - e sendo, também, senso comum entre eles -, como mais qualificadas para fornecerem diretrizes (ou receitas) a serem aplicadas nas salas de aula.

Nesta direção, é muito frequente a rejeição das novas propostas e dos novos modelos, "elaborados por um grupo de estranhos que afirmam ser especialistas na produção de conhecimentos válidos sobre a prática educativa" (ELLIOT, 1993, p. 63). Entende-se essa rejeição tanto como uma defesa, mesmo que inconsciente, de seu conhecimento e autonomia profissionais, como também uma manifestação guiada pela insegurança em relação às "ousadias" propostas. $\mathrm{O}$ autor identifica essa rejeição como um problema da relação prática-teoria e é, para ele, a razão para a manutenção das insatisfações dos professores com o seu trabalho.

Para superar essa realidade, entendemos que a formação continuada deve envolver alunos-professores e formadores de professores em processos de aprendizagem mútua a partir do reconhecimento de suas culturas profissionais enquanto saberes práticos de relevância, além da estruturação das atividades de formação como processos de pesquisa-ação. Tais ações têm o objetivo de: conhecer os contextos da sala de aula, promover o diálogo e a comparação entre as diversas concepções e destas com referenciais teóricos, assim como orientar alguma reformulação nas práticas docentes.

Uma experiência neste sentido está em andamento na UFPel, com o curso de especialização em Ensino de Ciências e Matemática, já em sua segunda edição nesta instituição. A hipótese curricular ${ }^{4}$ desse curso está estruturada de acordo com referenciais teóricos do Proyec-

\footnotetext{
${ }^{4}$ Utiliza-se, no âmbito do referencial teórico adotado, o termo hipótese curricular em lugar de planejamento curricular, pois este é aqui entendido como uma possibilidade de trabalho, entre outras, a ser desenvolvida e avaliada continuamente em um contexto concreto, permitindo ajustes, acréscimos e supressões.
} 
to Curricular IRES (GRUPO DIDÁCTICA E INVESTIGACIÓN EM LA ESCUELA, 1991), apresentando, como eixo central, uma concepção investigativa da prática docente coerente com um modelo de investigação na escola (PORLÁN e RIVERO, 1998) e sua estruturação a partir de problemas prático-profissionais.

Desta forma, o presente trabalho tem como objetivos: a explicitação dos referenciais orientadores e a organização da hipótese curricular para a evolução do conhecimento profissional dos professores. Aqui se consideram as primeiras percepções dos alunos-professores, decorridos praticamente dois terços do curso.

\section{Concepções sobre a formação de professores}

Para analisar a constituição do conhecimento profissional dos professores e planejar processos para o seu desenvolvimento, entendemos que a prática docente "manifesta as concepções de ensino, aprendizagem e de conhecimento, como também as crenças, sentimentos e compromissos políticos e sociais" dos professores (ARAGÃO, 1995 apud SCHNETZLER, 2004, p. 50), nem sempre de forma explícita e consciente.

Essas crenças, atitudes, valores e, também, as concepções didático-metodológicas sobre ensino, aprendizagem, conhecimento científico e avaliação, organizam-se em esquemas de ação que referenciam as práticas docentes e lhes dão sentido. Por estas razões, são definidos como modelos didáticos pessoais (PORLÁN e RIVERO, 1998).

Embora existam variados critérios para caracterizar os modelos didáticos pessoais dos professores (MALDANER, 2000; ROSA e SCHNETZLER, 2003; CIRINO, 2006), optamos pelas análises de Porlán e Rivero (1998), que caracterizam tais modelos de acordo com as concepções didático-epistemológicas que os fundamentam, analisando-os conforme uma perspectiva evolutiva. Esta apresenta um nível de partida (modelo tradicional), dois níveis de transição (modelos tecnológico e espontaneísta) e um nível desejável (alternativo ou de referência). Em cada nível, os objetivos do processo educacional em relação às finalidades (para que ensinar?), à metodologia da sala de aula (o quê e como ensinar?) e à avaliação se tornam complexos a partir do modelo tradicional.

$\mathrm{Na}$ caracterização adotada no presente trabalho, o modelo tradicional apóia-se na primazia do saber acadêmico subordinado a uma concepção do conhecimento científico como superior e verdadeiro, produzido pela racionalidade científica e identificado com um absolutismo epistemológico. Por consequência, a aprendizagem está fundamentada na substituição de conhecimentos e na apropriação de significados abstratos e formais de caráter hegemônico (cientificismo). Desta forma, são priorizados o saber disciplinar, bem como a sua exposição ordenada e controlada por parte do professor, em detrimento dos objetivos do ensino e da metodologia. Nessa perspectiva, para aprender, é necessário apenas apropriar-se dos significados verdadeiros dos conceitos pertencentes às diferentes disciplinas, sendo transmitidos tal qual foram aprendidos. Essas concepções e práticas educativas são ainda majoritárias no cotidiano de nossas escolas, sobretudo por ser este, também, o modelo formativo ainda vigente nos cursos de formação inicial de professores, segundo Porlán e Rivero (1998).

No contexto do primeiro modelo de transição possível, denominado tecnológico, fazse uma crítica racional ao modelo tradicional a partir da primazia do saber técnico. Privilegia- 
se um conhecimento que é assimilado cumulativamente e reproduzido de maneira eficaz a partir do domínio de competências, de habilidades instrumentais e de saberes funcionais. As propostas formativas enfatizam sequências e itinerários fechados, rigorosos, desenvolvidos em nível crescente de dificuldades, priorizando os conteúdos disciplinares em detrimento de discussões metodológicas e dos objetivos elencados para o ensino.

Por sua vez, o segundo modelo de transição possível é chamado modelo espontaneísta, estruturado a partir de uma crítica ideológica ao modelo tradicional. Fundamenta-se na primazia do saber fenomenológico, valorizando a experiência e o saber-fazer profissional como um conjunto de experiências advindas do contexto escolar. Nestes modelos, em "uma circularidade recorrente" (PORLÁN e RIVERO, 1998, p. 40), a prática profissional nutre a si mesma. A aprendizagem é espontânea e a apropriação de significados ocorre a partir da experiência docente. O planejamento de atividades é uma resposta direta aos problemas observados na sala de aula. Os marcos referenciais psicopedagógicos e as metodologias universais são rechaçadas (relativismo não-fundamentado). Referenciado pelas concepções deste modelo didático, entende-se o professor como um orientador/coordenador de atividades cujo início e fim são definidos de acordo com os interesses dos alunos. Privilegiam-se as aprendizagens procedimentais e a aquisição de atitudes e de valores, já que o aluno é o centro do processo.

De acordo com Porlán (1999), os modelos didáticos anteriores apresentam limites relacionados tanto pela desconsideração do conhecimento profissional dos professores quanto pelo reducionismo fenomenológico. O primeiro deles "impede reconhecer a natureza específica e diferenciada dos problemas docentes" (PORLÁN, 1999, p. 139), enquanto o segundo, "bloqueia a necessária interação crítica e enriquecedora entre o mundo da experiência e o da produção científica" (PORLÁN, 1999, p. 139). A consequência da existência desses limites verifica-se na forma justaposta segundo a qual os saberes acadêmicos e experienciais, as rotinas de ação e as teorias implícitas do professor estruturam seu conhecimento profissional.

Assim, Porlán e Rivero (1998) propõem, com base nestas considerações epistemológicas e didáticas, um modelo de formação profissional desejável (alternativo ou de referência), que possa superar os limites dos modelos anteriores e fundamentar a constituição de um conhecimento profissional de referência, entendido como capaz de propor metodologias e ações didáticas embasadas em atividades de investigação e de resolução de problemas relevantes. Estes princípios estão fundamentados na concepção do conhecimento profissional dos professores como "um âmbito epistemológico de integração de distintos tipos de saberes" (ibidem), e em concepções metodológicas derivadas da pesquisa-ação (ELLIOT, 1993). Os processos formativos desenvolvem-se de acordo com uma perspectiva evolutiva e construtivista do conhecimento, assim como uma perspectiva sistêmica, complexa e crítica da realidade da sala de aula e do seu contexto.

Expressos no Projeto Curricular IRES, estes princípios referenciam um "modelo didático de investigação na escola" (PORLÁN e RIVERO, 1998), uma proposta de formação inicial e de educação continuada. Têm como objetivo fundamental favorecer a evolução do conhecimento profissional dos professores segundo uma hipótese de progressão orientada por um conhecimento profissional de referência, com potencialidade para subsidiar um novo modelo didático pessoal.

Portanto, segundo esses referenciais, a formação dos professores seria um processo de (re)construção gradual e contínua de seu conhecimento profissional, cuja intencionalidade des- 
tina-se à construção de estratégias para a superação dos problemas da prática cotidiana. Esta construção, concebida evolutivamente, deve desenrolar-se em um contexto de explicitação, reflexão e discussão sobre seu conhecimento profissional prévio e seu confronto com novas concepções, para possibilitar mudanças ao mesmo tempo conceituais, metodológicas e atitudinais nos professores.

Neste caso, a evolução é entendida como a passagem de concepções e ações docentes, inicialmente simples e na maioria das vezes implícitas, relacionadas com o modelo didático tradicional, para outras progressivamente mais complexas e conscientes, "embasadas em uma visão integradora das relações entre ciência, ideologia e cotidianidade e no desenvolvimento dos princípios de autonomia, diversidade e negociação rigorosa e democrática de significados" (PORLÁN e RIVERO, 1998, p. 56), concepções que fundamentam a hipótese curricular do curso de especialização em Ensino de Ciências e Matemática, conforme se descreve a seguir.

\section{A educação continuada de professores de ciências e matemática: uma proposta}

O curso de especialização em Ensino de Ciências e Matemática da FaE-UFPel, cuja hipótese curricular será descrita a seguir, iniciou suas atividades em setembro de 2006, com 27 alunos-professores que exercem suas atividades profissionais em Pelotas (15 professores) e em mais sete municípios da Região Sul. Majoritariamente, licenciaram-se em Matemática (16), mas também em Ciências Biológicas (seis), Ciências (quatro) e Química (um), com atuação, predominantemente, no Ensino Fundamental (vinte) e, também, nas redes municipal (16) e estadual (oito).

O desenho curricular e os objetivos das atividades estão referenciados pelo modelo formativo proposto pelo Proyecto IRES (PORLÁN e RIVERO, 1998). Estes encontram-se fundamentados em processos de explicitação, reflexão e reconstrução do conhecimento profissional dos professores de acordo com uma dinâmica ativa de seu envolvimento efetivo neste processo de formação. Acreditamos que isso pode favorecer, de maneira significativa, a evolução dos seus conhecimentos profissionais.

Com base nas ações pedagógicas desenvolvidas, propõem-se novos papéis para o professor no desenvolvimento das atividades de sala de aula: o de facilitador da aprendizagem de seus alunos e, ainda, o de investigador dos processos didático-pedagógicos, tendo como objetivo a sua qualificação docente.

De acordo com esses enfoques, o curso de especialização tem sua estrutura curricular - ou, como denominada aqui, hipótese curricular -, organizada em focos conceituais (ou blocos ou disciplinas). Tais blocos orientam-se por estratégias didáticas relacionadas com momentos metodológicos organizados em ordem crescente de complexidade, às quais se associam, de acordo com o referencial teórico adotado, eixos de mudanças pretendidos para os professores, conforme se pode observar na Tabela 1. 
Rodrigues, C. G.; Krüger, V.; Soares, A. C.

Tabela 1. Hipótese curricular.

\begin{tabular}{|c|c|c|c|c|}
\hline Estratégia & $\begin{array}{l}\text { Eixo de } \\
\text { mudança }\end{array}$ & $\begin{array}{l}\text { Tipo de } \\
\text { professor }\end{array}$ & Formação & Momento metodológico \\
\hline Dinamização & Atitudinal & Interessado & Dirigida & $\begin{array}{l}\text { Conhecimento dos } \\
\text { problemas da prática e } \\
\text { relações com pressupostos } \\
\text { teóricos }\end{array}$ \\
\hline Apoio à inovação & Prática & Inovador & Dirigida & Evolução das concepções \\
\hline $\begin{array}{l}\text { Projetos de } \\
\text { experimentação curricular }\end{array}$ & Currículo & Agente curricular & Semidirigida & $\begin{array}{l}\text { Planejamento e } \\
\text { desenvolvimento de } \\
\text { hipóteses curriculares }\end{array}$ \\
\hline $\begin{array}{l}\text { Programas de } \\
\text { investigação educativa }\end{array}$ & Metodológico & Investigador & Heteroformação & Metarreflexão \\
\hline
\end{tabular}

O ponto de partida para esta hipótese curricular é a concepção de que o professor que procura um curso de especialização é um professor insatisfeito com a sua prática. Como a natureza desta prática nem sempre é um conhecimento do qual o professor está consciente, é necessário que se promovam, de início, atividades para a explicitação das concepções que referenciam sua prática docente (modelo didático pessoal), além da relação dos problemas identificados no seu cotidiano com referenciais teóricos e com as práticas de outros professores. Esta é a etapa de "dinamização" ou motivação inicial, cujo eixo de mudança é atitudinal, tendo, como objetivo, criar condições para favorecer mudanças conceptuais e a reconstrução das concepções didático-metodológicas.

Por isso, a disciplina inicial deste curso é denominada Didática e Prática de Ensino de Ciências e de Matemática I, com 75 horas-aula. Seu foco, conforme já se comentou, é o de fazer um inventário das crenças pedagógicas, metodológicas, científicas e epistemológicas dos professores visando à explicitação de um modelo didático pessoal de partida. Este modelo didático é conhecimento de referência para a compreensão das ações docentes e dos problemas que têm em suas atividades, sendo o fundamento dos processos de reflexão, da discussão sobre o ensino e a aprendizagem que se seguem.

Implicitamente, esta primeira estratégia pretende que os professores referenciem suas ações na sala de aula, ao mesmo tempo em que se conscientizam dos limites de suas concepções (seu modelo didático) para resolver problemas em sua ação profissional cotidiana. Também se pretende o contraste de outros modelos e propostas de ensino com o modelo didático pessoal dos professores, proporcionando o início de processos de comparação e de avaliação das possibilidades e potencialidades de novos modelos (ou concepções) como referentes para a resolução de problemas derivados dos limites de seus modelos pessoais. Espera-se que essas discussões sejam intensificadas a partir da etapa seguinte, de apoio à inovação.

A etapa denominada apoio à inovação é constituída por disciplinas de aprofundamento, num total de 180 horas-aula, que têm como eixo de mudança pretendido a prática docente. Pretende-se que mudanças nas práticas docentes dos professores ocorram a partir do desenvolvimento de blocos conceituais destinados a fundamentar mudanças conceptuais na natureza das práticas docentes a partir de subsídios para a superação dos problemas relacionados com a prática profissional, sobretudo: o absolutismo epistemológico, as concepções line- 
ares e fechadas de currículo, transmissivo/receptivas da aprendizagem, terminais e classificatórias para a avaliação.

Nestes blocos ou disciplinas de aprofundamento, pretende-se subsidiar mudanças conceptuais e a evolução das concepções didático-metodológicas dos professores, além de favorecer a construção de referenciais teóricos para a fundamentação de propostas curriculares inovadoras. Os blocos conceituais, com 45 horas-aula cada, são: História, Filosofia e Sociologia das Ciências; Temas Interdisciplinares de Ciências e Matemática; Teorias da Aprendizagem e Teorias Curriculares.

A essas disciplinas de aprofundamento, seguem-se os blocos conceituais focados na discussão e no planejamento de hipóteses curriculares diferenciadas para o ensino de Ciências e de Matemática. Estas serão desenvolvidas nas salas de aula destes professores, ao mesmo tempo em que ocorrerão tanto a investigação educativa como a avaliação curricular. O relatório do desenvolvimento dos projetos de inovação curricular e da reflexão sobre seus resultados, além das análises das propostas de investigação educativa e de avaliação curricular, é o enfoque central do trabalho de conclusão do curso de especialização.

Para subsidiar a elaboração dos projetos curriculares de investigação educativa e avaliação curricular a serem aplicados, desenvolver-se-ão, concomitantemente, os blocos (ou disciplinas) de Metodologias para o Ensino de Ciências e de Matemática, num total de 45 horas distribuídas entre atividades de construção textual e de discussões sobre a consideração das idéias prévias dos alunos, bem como a disciplina de Didática e Prática de Ensino de Ciências e Matemática II com 45 horas. Este período é destinado à elaboração destas hipóteses curriculares diferenciadas. A estes blocos, seguir-se-á o período, não-presencial, de aproximadamente um bimestre, destinado à aplicação dos projetos curriculares nas escolas e ao levantamento dos dados que possibilitarão sua avaliação.

Assim, ao assumirmos esta hipótese de progressão do conhecimento profissional dos professores, propomos um processo de educação continuada que possa ser permanente por promover a formação de profissionais "emancipados da submissão ao hábito e à tradição e possuidores de destrezas e de recursos que os habilitem a refletir sobre as suas ações com mais coerência e racionalidade e formular teorias baseadas na realidade de sua prática educativa" (CARR e KEMMIS, 1988, p. 136). Ao mesmo tempo, este processo formativo constitui uma investigação da hipótese de progressão e das estratégias correspondentes, as quais, esperamos, possam favorecer a evolução do conhecimento profissional dos professores em direção ao conhecimento desejado, segundo os referenciais teóricos adotados.

Como estratégia inicial de análise da hipótese curricular proposta, utilizamos um questionário com três questões, solicitando a avaliação dos alunos-professores sobre as percepções relativas aos seus processos de formação, conforme se detalha a seguir.

\section{Percepções dos professores sobre seus processos de formação}

Conforme já foi comentado, decorridos aproximadamente dois terços do período previsto para o curso de especialização, realizamos um primeiro questionamento sobre as percepções dos professores-alunos do curso sobre o processo de formação do qual estavam participando, o que foi feito a partir de um questionário com três questões: 
a) Considerando os blocos temáticos e a natureza das atividades desenvolvidas até o momento, a proposta desenvolvida está atendendo às expectativas que você manifestou quando da entrevista de seleção? Por quê? b) Em que medida o desenvolvimento deste curso está favorecendo mudanças em sua prática pedagógica? Quais? c) Que experiências/atividades desenvolvidas no curso são consideradas como as mais significativas para o seu desenvolvimento profissional? Exemplifique.

O questionário foi respondido por 16 alunos, de um total de 27. A orientação fornecida estabeleceu que o instrumento deveria ser preenchido em horário de aula. Para minimizar qualquer interpretação precipitada de que o documento caracterizasse uma avaliação, a ser posteriormente revertida em nota ou quantidade demonstrativa de suas aprendizagens, solicitamos que seus nomes não fossem revelados no instrumento.

Como já foi discutido, a composição curricular do bloco temático que estava sendo desenvolvido tem, como objetivos: a promoção da evolução das concepções dos professores sobre teorias do conhecimento, da aprendizagem, de currículo e sobre os modos de avaliar, além da construção de referências teóricas para a fundamentação das propostas curriculares inovadoras a serem desenvolvidas pelos docentes em formação como um dos pré-requisitos para conclusão do curso de especialização.

Desta forma, entendemos que a oferta de conhecimentos específicos em relação dialógica com as vivências dos sujeitos em formação, que foram resgatadas e sistematizadas no bloco anterior, isto é, com as experiências da vida profissional compartilhadas com os colegas e os professores do curso, configura subsídios básicos para o delineamento das inovações didático-curriculares esperadas. É, pois, importante identificar a natureza das percepções que os professores-alunos construíram até este momento para se poder subsidiar as novas ações desta hipótese curricular.

Podemos destacar, no que tange às percepções identificadas na primeira questão, que somente um(a) aluno(a) afirmou que "esperava um direcionamento mais objetivo do curso e direcionado à sua área de atuação". Por sua vez, nove alunos(as) revelaram que suas expectativas estão sendo atendidas, declarando "que a matemática já não é mais um bicho-papão", conseguindo repassá-la de forma diferente e mais interessante. Outros declararam que "o curso tem feito refletir muito $e$ modificar condutas em sala de aula". Os professores agora estão "prestando mais atenção nos métodos". Já, para seis alunos, o curso vem superando suas expectativas, pois estão refletindo mais sobre suas práticas pedagógicas, o que "mudou atitudes frente a algumas situaçoes". Os professores indicaram que "têm refletido e revisto a sua atuação como educadores", "descobrindo coisas novas que influenciam diretamente no trabalho docente", coisas que antes não conseguiam perceber.

Por sua vez, foi também possível reconhecer alguns movimentos potencializadores do trabalho docente e favorecedores de mudanças conceptuais, relacionados, sobretudo, com: a ampliação de conhecimentos teóricos, a capacidade de problematizarem suas práticas docentes, as mudanças na relação professor-aluno que introduziram em suas salas de aula, assim como os procedimentos utilizados para a avaliação da aprendizagem. Neste sentido, uma das professoras destacou que, para ela, uma das experiências mais significativas foi o fator "nãoprova", sendo substituída por "muita leitura, posicionamentos, relatórios e comprometimento". Ela evidenciou que esse procedimento produziu mudanças nas concepções de avaliação colocadas em prática nas salas de aula, que mudaram seus processos de avaliação para "progressivos e qualitativos". 
De acordo com o referencial adotado, entendemos que o processo de formação de um professor não se resume à oferta de conhecimentos específicos da sua área de atuação e, muito menos, de conhecimentos ou técnicas pedagógicas. Por isso, a hipótese curricular deste curso de especialização está focada nos aspectos didático-metodológicos em estreita ligação com conteúdos específicos e com a prática docente dos sujeitos envolvidos, de modo a favorecer, gradativamente, novas formas de ver, dizer e agir - mais especificamente, nas respostas dos questionários, o que se verificou nas manifestações dos professores.

Se, em um primeiro momento do curso, o objetivo maior é identificar os problemas da prática profissional expressos no dia-a-dia, caracterizar os modelos didáticos pessoais dos professores e, com isso, relacionar tais problemas com estes modelos; em um segundo momento, a discussão de referenciais teóricos serve como subsídio para os sentidos construídos sobre as relações estabelecidas anteriormente. Insistimos na inversão da lógica acadêmica que sobrepõe o conhecimento científico e técnico às vivências professorais, de modo a fomentar a participação do professor na construção da sua trajetória docente em conjugação com o conhecimento científico, com o contexto escolar e com as práticas coletivas que o circundam. Estamos cansados de propostas de formação baseadas em técnicas que se agarram às tecnologias pedagógicas produzidas por especialistas para consertar a educação. Estamos cansados, mais ainda, dos perfis desejados, das competências prescritas, estratificadoras de identidades organizadas em torno de uma representação dada a priori.

Por tais motivos, apostamos na formação continuada de professores, deixando, primeiramente, vir à tona as sensações de insatisfação e impotência que abatem tais sujeitos, as forças que os afetam, despotencializando o poder disruptivo das atividades docentes, assim como suas verdades sobre os processos de ensino e de aprendizagem. Somente depois desse período, em que é priorizado o "desentupimento" de práticas e de pensamentos professorais estratificados, apostamos na oferta e nos estudos de referenciais teóricos relativos à história, filosofia e sociologia da ciência, o currículo e a aprendizagem. Com isso, os alunos-professores vão, aos poucos, sentindo-se encorajados para acolherem os abalos provocados pela tomada de consistência nos novos territórios habitados, mesmo que, por vezes, ainda se situem em suas fronteiras, conforme se manifesta uma aluna: "antes do curso, eu não teria coragem de manifestar desta ou daquela maneira... Seguidamente me surpreendo buscando razões ou motivos para direcionar as minhas aulas. Sempre que preciso justificar uma decisão, busco informacōoes nos teóricos estudados".

Com Garcia e Porlán (1997) entendemos as trajetórias de evolução que estão sendo evidenciadas nestas falas e os diferentes níveis de complexidade que são percorridos pelo professor em processo de formação continuada. O primeiro nível, ou estágio, tem como característica principal a tomada de consciência do professor em formação continuada sobre seu sistema de ideias a respeito dos processos de ensino e de aprendizagem, que, em consonância com os autores acima citados, entendemos como um modelo didático pessoal. O segundo estágio caracteriza-se pelo reconhecimento e crítica dos problemas, dilemas e obstáculos da prática profissional. E, para o terceiro momento, os autores sinalizam a necessidade de o professor em formação retornar aos estudos para construir novas compreensões teóricas para suas reflexões, em contraste com suas concepções anteriores e com as experiências compartilhadas com o grupo.

Será a partir desses níveis, habitados gradativamente, que o professor colocará, em prática, suas hipóteses de intervenção e os procedimentos para executá-las desde a organiza- 
ção de processos curriculares e de avaliação investigativa da aprendizagem dos seus alunos. Após vivenciar o exercício de intervenção educativa, o professor em formação continuada poderá vir a contrastar suas hipóteses iniciais com os resultados obtidos com a nova experiência docente, e destes com o modelo didático de referência construído a partir dos estudos realizados em relação a sua prática docente. Garcia e Porlán (1997) indicam que também é possível que os docentes elaborem conclusões, comunicações e reconfigurem antigas e novas tensões oriundas do seu trabalho em sala de aula.

O esquema teórico aqui utilizado, juntamente com as análises realizadas a partir das percepções manifestadas pelos alunos, comparadas com suas concepções iniciais acerca do curso, fazem-nos pensar que pedagogia e vida estão em intensa articulação na formação de professores. A proposta curricular potencializadora das concepções didático-metodológicas de professores de Ciências e de Matemática, desenvolvida na FaE-UFPel, faz-nos ver que o ato de formar professores em serviço se dá na conexão do processo vital com a criação de paisagens conceituais. É nessa articulação que são produzidos sentidos para aquilo que nos habita no dia a dia da sala de aula e incentivadas as mudanças conceptuais de complexificação da prática docente. Neste sentido, verificou-se que, conforme havia sido previsto na hipótese curricular, mais efetivas foram as mudanças atitudinais nas reflexões sobre suas práticas docentes e nas metodologias em sala de aula.

Queremos ainda destacar que as experiências mais significativas no curso, incentivadoras do desenvolvimento profissional dos professores, referem-se, em primeiro lugar, à importância dos debates no grande grupo e a troca de ideias, conforme depoimento de um aluno: "Na minha opinião as discussões no grande grupo e as exposições das práticas pedagógicas dos colegas ajudam no meu desenvolvimento". Isso evidencia quão renovador é quando sentimos que nossas falas ecoam, quando nos percebemos autoconfiantes e quando nos sentimos estimulados a procurar evidências, para que se rompam os padrões estabelecidos pela estrutura, que tende a nos "engessar" e manter-nos inertes.

Os alunos-professores, também, destacam a importância da avaliação formativa, do comprometimento deles e dos professores-formadores do curso, além do seu acesso às leituras, como fatores importantes na evolução de seus conhecimentos profissionais. Segundo eles, essas atividades proporcionam a ocorrência da percepção sobre seus saberes profissionais e tomadas de consciência dos problemas da prática docente, o que potencializa a geração de mudanças atitudinais já comentadas.

Ainda segundo esses professores, as mudanças atitudinais que identificam em suas concepções e práticas também são favorecidas: pelo compromisso dos professores do curso, pela sua visão de ensino-aprendizagem e pelos estudos tanto das teorias curriculares como também das teorias da aprendizagem - o que, aliado ao olhar crítico e à possibilidade da reformulação e da reescrita de suas concepções e práticas, reforça nossa convicção de que, tão importante quanto o conteúdo disciplinar, é também a integração entre os diferentes saberes que estruturam o conhecimento profissional dos professores, pois isto permite que estes “[...] reinterpretem os conhecimentos científicos e psicopedagógicos para explicar os processos de ensino e aprendizagem [...]" (PORLÁN e RIVERO, 1998, p. 82).

Percebemos, finalmente, que, a partir das manifestações realizadas pelos alunos-professores, evidencia-se, neste momento, ainda muito em nível teórico, o desenvolvimento de um outro professor, que manifesta uma grande preocupação com os processos de aprendiza- 
Uma hipótese curricular para a formação continuada ...

gem de seus alunos, e que busca caminhos para romper com as dificuldades que se manifestam no seu cotidiano profissional. Este professor, já desacomodado dos hábitos e costumes de senso comum, ainda majoritários em nossas escolas, começa a tomar consciência das suas possibilidades de mudança, tanto em suas concepções pessoais, como também na sua prática concreta, promovendo o estabelecimento de reflexões críticas e a construção de modelos didáticos mais favoráveis para referendar as suas práticas docentes. São esses elementos que nos vêm permitindo afirmar que a hipótese curricular e a de progressão propostas são ações que, efetivamente, provocam a complexificação dos modelos didáticos dos professores e, por consequência, de suas práticas pedagógicas, conforme os objetivos do curso de especialização em Ensino de Ciências e de Matemática da FaE-UFPel.

\section{Referências}

CARR, W.; KEMMIS, S. Teoría crítica de la enseñanza. Barcelona: Martínez Roca, 1988.

CIRINO, M. M. Considerações sobre práticas de sala de aula no ensino de Ciências: uma abordagem comparativa. Revista Diálogo Educacional, Curitiba, v. 6. n. 18, p. 169-181, 2006.

ELLIOT, J. El cambio educativo desde la investigación-acción. Madrid: Morata, 1993.

GARCIA, J. E.; PORLÁN, R. Hacia una teoría del conocimiento profesional. In: CONGRESSO INTERNACIONAL DE DIDÁCTICA DE LAS CIÊNCIAS, 5., 1997, Barcelona. Atas... Barcelona: Enseñanza de las Ciencias, 1997. p. 77-90.

GRUPO INVESTIGACIÓN EN LA ESCUELA I. E1 modelo didáctico de investigación en la escuela. Proyecto Curricular Investigación y Renovación Escolar (IRES). Sevilla: Polígrafo, 1991a.

II. E1 marco curricular. Proyecto Curricular Investigación y Renovación Escolar (IRES). Sevilla: Polígrafo, 1991b.

III. El curriculo para la formación permanente del profesorado. Proyecto Curricular Investigación y Renovación Escolar (IRES). Sevilla: Polígrafo, 1991c.

MALDANER, O. A. A formação inicial e continuada de professores de Química: professores/pesquisadores. Ijuí: Unijuí, 2000.

PORLÁN, R. La formación permanente del profesorado: análisis de un programa institucional. In: CERDÁN VICTORIA, J.; GRAÑERAS PASTRANA, M. (Orgs.). La investigación sobre el profesorado (II): 1993-1997. Madrid: Ministério de Educación y Cultura/CIDE, 1999. p. 136-155.

PORLÁN, R.; RIVERO, A. El conocimiento de los profesores. Sevilla: Díada, 1998. 
Rodrigues, C. G.; Krüger, V.; Soares, A. C.

ROSA, M. I. P.; SCHNETZLER, R. A investigação na formação continuada de professores de ciências. Ciência e Educação, Bauru, v. 9, n. 1, p. 27-39, 2003.

SCHNETZLER, R. A pesquisa no ensino de Química e a importância da Química Nova na escola. Química Nova na Escola, São Paulo, n. 20, p. 49-54, 2004.

Artigo recebido em março de 2009 e aceito em junho de 2010. 